\title{
Optimizing therapeutics in the management of patients with multiple sclerosis: a review of drug efficacy, dosing, and mechanisms of action
}

This article was published in the following Dove Press journal:

Biologics: Targets and Therapy

26 November 2013

Number of times this article has been viewed

\section{Kavitha Damal \\ Emily Stoker \\ John F Foley}

Rocky Mountain Multiple Sclerosis Research Group, Salt Lake City, UT, USA
Correspondence: John F Foley Rocky Mountain Multiple Sclerosis Research Group, 370 East 9th Avenue - Suite 106, Salt Lake City, UT 84103, USA

Tel + I 80I 4085700

Email jfoley@rockymountainmsclinic.com
Abstract: Multiple sclerosis (MS) is a debilitating neurological disorder that affects nearly 2 million adults, mostly in the prime of their youth. An environmental trigger, such as a viral infection, is hypothesized to initiate the abnormal behavior of host immune cells: to attack and damage the myelin sheath surrounding the neurons of the central nervous system. While several other pathways and disease triggers are still being investigated, it is nonetheless clear that MS is a heterogeneous disease with multifactorial etiologies that works independently or synergistically to initiate the aberrant immune responses to myelin. Although there are still no definitive markers to diagnose the disease or to cure the disease per se, research on management of MS has improved many fold over the past decade. New disease-modifying therapeutics are poised to decrease immune inflammatory responses and consequently decelerate the progression of MS disease activity, reduce the exacerbations of MS symptoms, and stabilize the physical and mental status of individuals. In this review, we describe the mechanism of action, optimal dosing, drug administration, safety, and efficacy of the disease-modifying therapeutics that are currently approved for MS therapy. We also briefly touch upon the new drugs currently under investigation, and discuss the future of MS therapeutics.

Keywords: multiple sclerosis, immunomodulation, interferons, glatiramer acetate, monoclonal antibodies, dimethyl fumarate

\section{Introduction}

Multiple sclerosis (MS) is a complex and chronic demyelinating autoimmune neurological disorder that manifests through an interaction of environmental and genetic factors. ${ }^{1-5}$ The onset of MS occurs at an individual's most productive years (20-40 years), ${ }^{6,7}$ and affects considerably more women than men. ${ }^{8-10}$ A long-term follow-up study of MS reports a steady rise in the incidence of MS, while the age at onset of disease symptoms has been continuously decreasing. ${ }^{6}$ Nearly 2.5 million individuals worldwide (nearly one in every 400 individuals) are afflicted with MS, although experts consider this number to be an underestimation of true prevalence. MS is unquestionably a disabling disease that impairs both the physical function and cognitive ability of patients. ${ }^{11}$ While their longevity is not severely compromised (reduction in life span by 6-7 years), ${ }^{12}$ quality of life is significantly impacted, as individuals are plagued by MS-associated comorbidities, such as chronic pain, fatigue, depression, sleep disorders, spasticity, gait and coordination imbalances, migraines, sensory organ dysfunctions, and overall cognitive impairment. Since the description of MS by French neurologist Jean-Martin Charcot as a triad of symptoms (nystagmus, intention tremor, and slurred speech) ${ }^{13}$ in 1868 , research on the etiology, 
pathophysiology, and management of this disease has progressed dramatically, although a conclusive diagnostic marker or curative therapy still remains undefined.

\section{MS diagnosis and subtype classification}

Presently, a combination of paraclinical diagnostic investigations, including magnetic resonance imaging (MRI) assessment of brain-lesion dissemination in space and time, presence of oligoclonal bands in cerebrospinal fluid, delayed latencies in visual evoked potentials, and changes in retinal nerve fiber-layer thickness evaluated using optical coherence tomography alongside clinical symptoms, as recommended by the $2010 \mathrm{McD}$ onald criteria, are used to guide MS diagnosis. ${ }^{14-16}$ While several potential biomarkers are being studied to ascertain their utility in diagnosing MS, ${ }^{17,18}$ none has yet been determined as clinically useful. Furthermore, discovery of markers to establish prognosis based on disease symptoms and treatment trajectories is also wanting. ${ }^{19}$

A majority of MS patients ( $~ 85 \%)$ experience symptomatic attacks between dormant states ("remission"), commonly referred to as the relapsing-remitting type (RRMS), which may initially present as a clinically isolated syndrome. This may segue, after a number of years, into secondary progressive MS, marked by fewer or no relapses and gradual neurological worsening with brain atrophy. Primary progressive MS presents with a continuous neurological worsening from the first onset of symptoms. Despite their similarity, studies have identified distinct pathological differences ${ }^{20}$ that could be translated to determine treatment decisions and predict the prognosis for patients based on the subtype presentation. ${ }^{21,22}$ Of note, primary and secondary progressive forms have generally been more resistant to anti-inflammatory therapies when compared to RRMS subtype.

\section{Management of MS}

MS therapeutics divides into primary disease treatment using immunomodulating agents, which will be discussed in detail, as well as specific symptom management (eg, spasticity, fatigue, depression, pain, etc), which will not be further addressed in this review.

\section{Primary immunomodulatory therapeutics}

The goal of mainstay therapies of MS is to reduce relapses and postpone progression of disability in patients. ${ }^{23,24}$ To this end, strategies adopted to treat MS are twofold: a short-term treatment to help reduce the accumulation of disease burden after an acute relapse, and a long-term, sustained treatment aimed at stabilizing the disease process. ${ }^{25}$

\section{Short-term treatment for acute relapse}

In the initial stages of an MS relapse, individuals are generally treated with high doses (500-1,000 mg) of intravenous corticosteroids (eg, methylprednisolone) for a short period of 3-5 days. In rare cases, subcutaneous or intramuscular injections of adrenocorticotropic hormone (eg, HP Acthar ${ }^{\circledR}$ gel) are used, specifically for individuals who cannot tolerate or have poor response to intravenous prednisolone. ${ }^{26-28}$ These anti-inflammatory agents accelerate the process of recovery, and reduce duration of the relapse; however, they do not have any bearing on the occurrence of new relapses or on long-term disease progression..$^{27-30}$

\section{Long-term disease management}

The fundamental pathogenesis of MS is characterized by two stages of disease development. ${ }^{31}$ The inception of MS symptoms (clinical and paraclinical) and focal demyelination of neurons occur during the early inflammatory phase. The late neurodegenerative phase is characterized by further demyelination of neurons perpetrated by infiltrating macrophages, microglial cells, and lymphocytes that attack the endogenous myelin sheath proteins as antigens, leading to irreversible axonal loss. ${ }^{32}$ Given the role played by lymphocytes in advancing MS, long-term disease management is largely directed towards suppressing the immune-inflammatory responses that promote demyelination and neuronal degradation in an effort to prevent any saltatory changes in the status quo of patients. ${ }^{23,24,27,33}$ Outcomes of MS treatments are evaluated based on a reduction in MS annualized relapse rate (ARR), stabilization, or regression in Expanded Disability Status Scale (EDSS) score, and unchanged brain and spinal cord MRI lesion burden. ${ }^{34}$

Over the past decade, the disease-fighting armamentarium for MS has rapidly expanded with the discovery of new disease-modifying therapeutics (DMTs), which employ different mechanisms to slow or reverse inflammatory lesion formation. To date, regulatory agencies, such as the US Food and Drug Administration (FDA) and the European Medicines Agency, have approved nine different DMTs (Table 1) to aid with modifying the disease course in MS patients (http:// www.accessdata.fda.gov/scripts/cder/drugsatfda/index.cfm). Emerging evidence suggests some DMTs may be able to stabilize and perhaps even improve neurological status; however, they are not capable of completely relieving all symptoms of MS. ${ }^{23}$ Here, we briefly discuss the mechanism of action, optimal dosing, and efficacy of each of these DMTs. 


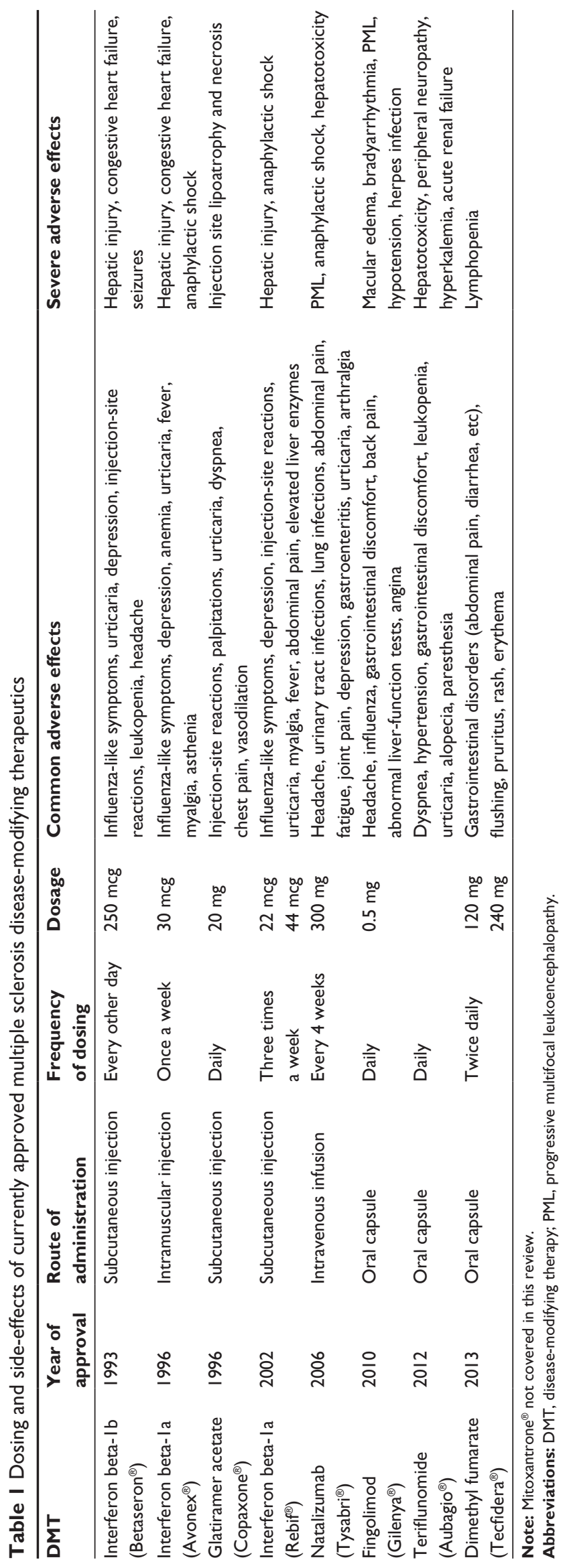

\section{Interferons}

Interferons (IFNs) are proteins that belong to the cytokine network and are involved with the regulation of immune response against microbial and viral antigens. ${ }^{35}$ Their immunomodulatory properties were leveraged to develop the first DMTs for MS, namely, IFN- $\beta 1$ b (Betaseron ${ }^{\circledR}$, Bayer HealthCare, Leverkusen, Germany; Extavia, Novartis, Basel, Switzerland), a fermented and purified recombinant protein produced in the bacterium Escherichia coli, ${ }^{36}$ and two preparations of IFN- $\beta 1$ a (Avonex ${ }^{\circledR}$, Biogen Idec Inc., Weston, MA, USA; Rebif ${ }^{\circledR}$, Merck Serono, Geneva, Switzerland), which are recombinant human IFN proteins produced in mammalian cells in a glycosylated form. ${ }^{27,37}$

In vitro studies using human isogenic $\mathrm{T}$ cell lines and murine experimental autoimmune encephalomyelitis (EAE; a disease very similar to MS) models and in vivo studies on humans (clinical trials) have elucidated the mechanism of action of IFN- $\beta$ to be as follows: ${ }^{37-39}$ IFN- $\beta$ suppresses the proliferation of myelin-basic protein-specific $\mathrm{T}$ cells, reduces the production of proinflammatory cytokines (eg, IFN- $\gamma$ ), and induces anti-inflammatory cytokines, such as interleukin (IL)-10. ${ }^{37,39,40}$ This results in a cytokine balance that protects neurons from demyelination by preventing the proliferation of $\mathrm{T}$ cells that are required for advancing the autoimmune process and inhibiting $T$ cells from crossing the blood-brain barrier (BBB) and entering the central nervous system (CNS). ${ }^{39,40}$ Both IFN- $\beta 1 \mathrm{~b}$ and IFN- $\beta 1 \mathrm{a}$ are equivalent with respect to their ability to reduce MS disease activity (Tables 1 and 2), and they reduce ARR by up to $30 \%$, decrease formation of new or enlarging gadolinium-enhancing MRI lesions by $50 \%$, and significantly lower the progression of EDSS scores. ${ }^{27,41-44}$

\section{Glatiramer acetate}

Demyelination of neurons in MS is mediated by activation of helper $\mathrm{T}$ cells in response to a specific myelin-basic protein (MBP), which is one of the autoantigens in MS. ${ }^{45,46}$ Peptides of MBP bind to class II major histocompatibility complex (MHC II) molecules, which are then recognized by $\mathrm{T}$ cells as antigens and consequently destroyed. ${ }^{47,48}$ In 1995, Copolymer 1 (glatiramer acetate [GA]/Copaxone ${ }^{\circledR}$; Teva Pharmaceuticals, Petach Tikva, Israel) was introduced as an alternate therapy to IFN- $\beta$. GA is a synthetic polymer of four amino acids (L-glutamate, L-lysine, L-alanine, and L-tyrosine) that mimics MBP, and hence competes with MBP antigens to bind with MHC II. ${ }^{27,49}$ Using human EpsteinBarr virus-transformed $\mathrm{B}$ cell lines, Fridkis-Hareli et a ${ }^{50}$ demonstrated in vitro that GA binds to MHC-II molecules 


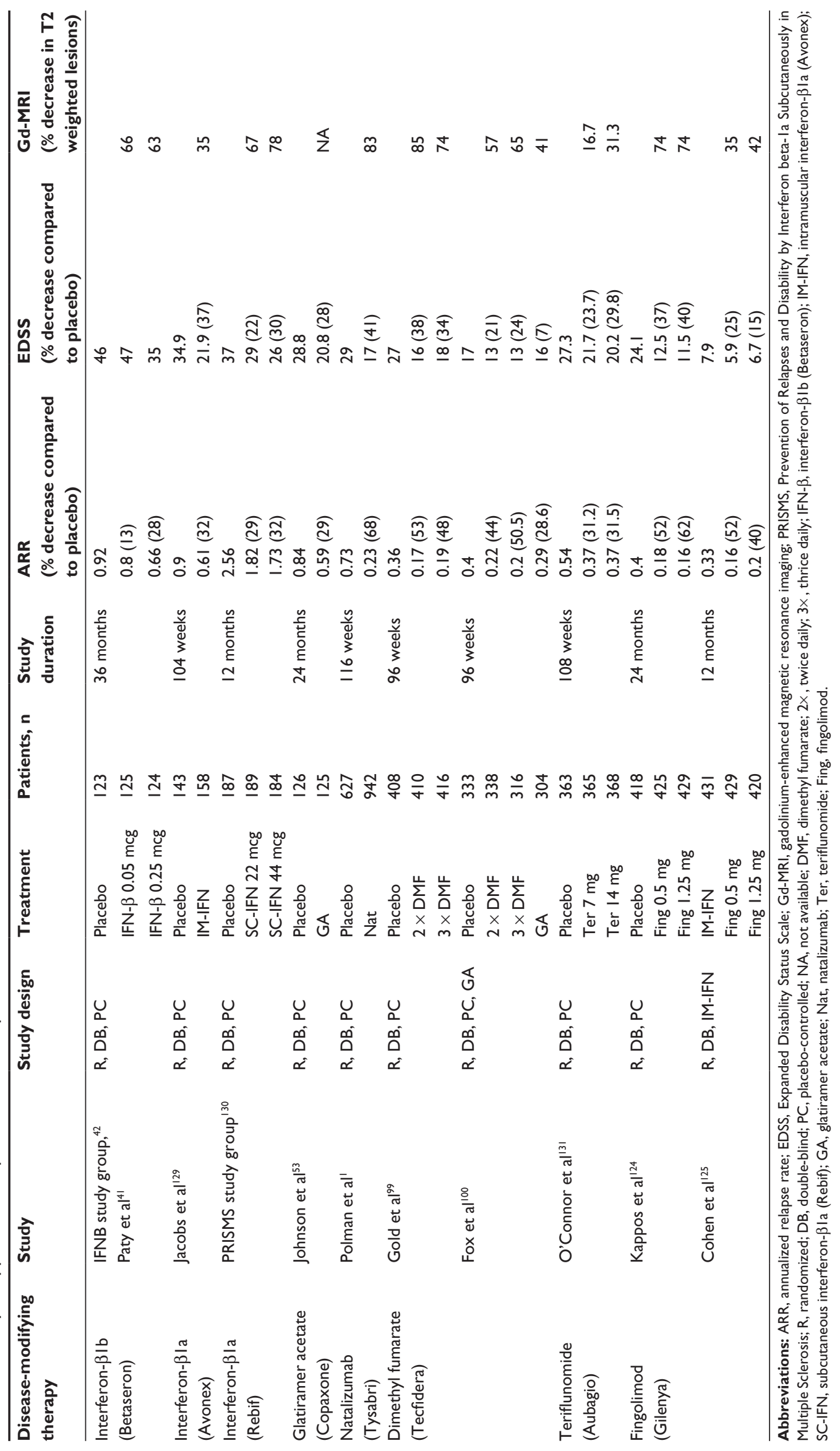


with high efficiency as well as at a fast rate. Thus, when the MHC-II molecules are blocked from binding to MBP, $\mathrm{T}$ cell responses are automatically diverted away from the myelin, resulting in neuronal protection. ${ }^{49,50}$ The proliferation of T cells is thus controlled by GA in a dose-dependent manner. ${ }^{51} \mathrm{MHC}-\mathrm{II}$ molecules interact with $\mathrm{CD} 4^{+}$molecules that are present on the surface of helper T cells (Th1 and Th2) that produce proinflammatory cytokine (Th1-type cytokines: INF- $\gamma$ ) and anti-inflammatory cytokine (Th2-type cytokines: IL-10) molecules. ${ }^{52}$ GA preferentially inhibits production of INF- $\gamma$, induces regulatory Th2-like $\mathrm{T}$ cell populations that cross-react with MBP, and produce anti-inflammatory cytokines, which in turn protects the myelin through a "bystander-suppression" mechanism. ${ }^{51} \mathrm{GA}$ is generally well tolerated and reduces ARR by $29 \%$; however, it was unable to reduce disability progression significantly when compared to placebo (Tables 1 and 2)..$^{53-55}$

Given their safety profile, low toxicity, reasonable efficacy, and relative tolerability, IFN and GA are often prescribed as first-line MS therapies. ${ }^{23,27}$ While a meta-analysis study in 2004 indicated that GA was not useful in treating $\mathrm{MS},{ }^{55}$ a more recent study substantiated its utility in treating relapses related to RRMS, but reiterated its limited impact on disability progression. ${ }^{56}$

\section{Natalizumab}

In the early $1990 \mathrm{~s}$, Yednock et $\mathrm{al}^{57}$ identified that monocytic cells selectively bound to inflamed blood vessels in the brain; the inflammation was caused by EAE. Using an EAE mouse model, they demonstrated that the selective adhesion of leukocytes to vascular cell adhesion molecule 1 (VCAM-1), a protein expressed on the surface of vascular endothelial cells in the brain and spinal cord, ${ }^{58}$ is a critical step to gain entry into the CNS across the BBB. Over 95\% of this adhesion was significantly inhibited by antibodies against the integrin molecule $\alpha_{4} \beta_{1}$ (very late-activation antigen 4 [VLA-4]), a glycoprotein surface molecule found on all leukocytes except neutrophils. ${ }^{57}$ Administration of the antibodies reduced the progression of inflammatory disease severity in MS patients (MRI lesions), ${ }^{59,60}$ and prevented the development of paralysis in animal studies.$^{61}$ Hence, it was hypothesized that monoclonal antibodies against VLA-4 could help with treating autoimmune inflammatory diseases such as MS by blocking the VCAM-1/VLA-4 interaction, and preventing infiltration of leukocytes across the BBB. ${ }^{57,58}$ In early 2000, natalizumab (Antegren; Elan, Dublin, Ireland, and Biogen Idec Inc.), an $\alpha_{4}$-integrin humanized monoclonal antibody to VLA-4, was developed. ${ }^{62}$ Natalizumab specifically targets the T cells ${ }^{63}$ and inhibits the $\alpha_{4}$-integrin-mediated firm adhesion of $\mathrm{T}$ cells to the inflamed BBB by $70 \%$, but does not interfere with the initial contact of $\mathrm{T}$ cells with the BBB, suggesting that the central mechanism of natalizumab action is prevention of T cell entry into the CNS. ${ }^{64}$

After establishment of the relative safety profile in a Phase I clinical trial, ${ }^{65}$ Phase II and Phase III doubleblind placebo-controlled trials demonstrated its efficacy in reducing ARR, especially in patients with higher disease activity. ${ }^{60,66}$ The FDA subsequently approved natalizumab (Tysabri; Biogen Idec Inc.) as an MS monotherapy in 2004 (http://www.accessdata.fda.gov/drugsatfda_docs/appletter/2004/125104 0000 1tr.pdf). However, the emergence of three cases of progressive multifocal leukoencephalopathy (PML) led to its withdrawal from the market for a brief period between February 2005 and June 2006. ${ }^{67,68}$ In 2006, the results of the Natalizumab Safety and Efficacy in Relapsing Remitting Multiple Sclerosis (AFFIRM) trial, ${ }^{1}$ with a follow-up of over 2 years, elucidated the superiority of natalizumab in controlling progression of MS (Table 2), resulting in reinstatement of natalizumab as an MS therapeutic., ${ }^{1,69}$ Natalizumab therapy also significantly improves the overall quality of life of RRMS patients (Table 2). ${ }^{70-74}$ The Safety and Efficacy of Natalizumab in Combination with Interferon Beta-1a in Patients with Relapsing Remitting Multiple Sclerosis (SENTINEL) study further reiterated the efficacy of natalizumab as a combination therapy with IFN- $\beta 1$ a (Table 2) than administration of IFN alone (Table 2). ${ }^{75}$

The principal limitation to natalizumab utilization has been PML, related to the mutation of the John Cunningham (JC) polyoma virus to a neurotrophic form. Postmarketing surveillance of natalizumab reported 377 incidences of $\mathrm{PML}^{76}$ across the world, and three principal factors have been identified to increase the risk of developing PML (therapy $\geq 24$ months, history of immunosuppressant treatment, and JC-antibody positivity) in patients undergoing natalizumab therapy. ${ }^{71,76,77}$ Further, recent studies show that higher-titer levels of JC virus antibody predispose to development of PML. ${ }^{78}$ Less well defined is the possible contribution of excessively low CD62L (L-selectin) expression on $\mathrm{CD}^{+}{ }^{+}$cell populations ${ }^{79}$ and the possible association between low body weight and increased PML risk, which are presently being studied extensively. ${ }^{80}$ Although its superior efficacy in modulating disease activity and progression has made natalizumab a reliable therapy for MS, the risk-to-benefit ratio of the drug varies dramatically among patients, and hence demands a more personalized approach to utilization. 


\section{Dimethyl fumarate}

Dimethyl fumarate (DMF; BG-12, Tecfidera ${ }^{\circledR}$; Biogen Idec Inc.) is a methyl ester of fumaric acid approved by the FDA as an oral MS therapy on March 27, 2013 (www.fda.gov/ NewsEvents/Newsroom/PressAnnouncements/ucm345528. htm). A well-known pathway to MS is oxidative stress brought about by the effector molecule peroxynitrite (reactive nitrogen species [RNS]). ${ }^{81}$ Macrophages, upon localization in the glial cells, release proinflammatory cytokines and free radicals to aid with host immune protection. ${ }^{82-84}$ The antimicrobial properties of Nitric Oxide (NO) are well established, ${ }^{85}$ but as a cytotoxic agent $\mathrm{NO}$ also leads to extensive host cellular damage. In inflamed regions, NO is released equivalently to the extent of inflammation: the more the inflammation, the more the NO released. ${ }^{86,87} \mathrm{NO}$ reacts with other free radicals like superoxide to produce RNS, ${ }^{82,88}$ which in turn induces oxidative damage to the mitochondrial deoxyribonucleic acid, ultimately resulting in decreased adenosine triphosphate production. ${ }^{89}$ Thus axonal transport, a process that requires adenosine triphosphate, and cellular respiration are impaired, leading to axonal degeneration and irreversible cell apoptosis. ${ }^{89}$

Initial in vitro studies highlighted the detoxification and anti-inflammatory capabilities of DMF, which reduces with the production and release of inflammatory molecules, such as cytokines and NO, and elevates the production of detoxification enzymes such as reduced-form nicotinamide adenine dinucleotide phosphate quinone reductase 1 and/or glutathione. ${ }^{83,88,90}$ Additional studies in EAE mouse models showed a DMF dose-dependent decrease in inflammatory cell infiltrates (composed of macrophages, microglial cells, and proinflammatory cytokines).$^{91} \mathrm{DMF}$ also inhibits the expression of VCAM-192 and activates nuclear factor erythroid 2-related factor (Nrf2), a transcription factor with antioxidant properties. Nrf2-mediated antioxidative stress response reduces the free radicals, prevents synthesis of RNS, and thus protects the CNS from degeneration and axonal loss. ${ }^{93}$ Thus, DMF preserves myelin integrity via two pathways: by downregulating oxidative stress and corresponding cellular injury, as well as by inhibiting proinflammatory cytokines. ${ }^{82,93-95}$

The first exploratory study of oral fumaric acid esters was performed in ten patients with RRMS in 2006. ${ }^{96}$ Promising results from this study led to the expansion of clinical research to apply BG-12, a second-generation fumarate derivative as a potential oral therapeutic for RRMS. ${ }^{97}$ Kappos et $\mathrm{a}^{98}$ demonstrated the safety and efficacy of DMF, showing a $69 \%$ reduction in gadolinium-enhanced MRI (Gd-MRI) lesions and a 32\% reduction in ARR when compared to placebo (Table 1). The Phase III trials DEFINE
(Determination of the Efficacy and Safety of Oral Fumarate in Relapsing-Remitting MS) ${ }^{99}$ and CONFIRM (Comparator and an Oral Fumarate in Relapsing-Remitting Multiple Sclerosis ${ }^{100}$ further elucidated the efficacy of DMF in reducing ARR by $53 \%$ and $44 \%$ compared to placebo or GA, respectively (Table 2), a decrease in Gd-MRI activity by $70 \%$, and a decrease in disability progression of $38 \%$ (Table 2 ). In addition, the side effects of DMF were relatively benign, including gastrointestinal discomfort, flushing, decreased lymphocyte count, and elevated liver aminotransferase levels (Table 1). ${ }^{99-101}$ Although some formulations and metabolites of fumaric acid esters are known to cause PML, ${ }^{102,103}$ DMF by itself has been suggested as a safe drug with relatively low side effects. ${ }^{104}$

\section{Teriflunomide}

Teriflunomide is the active metabolite of leflunomide, a chemical with known anti-inflammatory, anti-proliferative and immunosuppressive properties. ${ }^{105}$ The utility of oral teriflunomide in treating MS was realized in 2006 through a Phase II clinical study reported by O'Connor et al, ${ }^{106}$ which elucidated its immunomodulatory effects in decreasing MRI lesions and ARR in RRMS patients. Triggering of an immune response involves the proliferation of $\mathrm{T}$ cells and $\mathrm{B}$ cells to provide antigen-specific cell-mediated or humoral immunity, respectively. In order to activate the lymphocytes to undergo clonal expansion, adhesion of $\mathrm{T}$ cells to the antigen-presenting cells is a crucial step. ${ }^{107}$ Teriflunomide primarily acts by interfering with the lymphocyte cell cycle and inhibiting proliferation. Lymphocyte mitosis requires an eightfold increase in the level of pyrimidine ribonucleotides (eg, ribonucleotide uridine monophosphate) during the interphase of the cell cycle. A key enzyme, dihydroorotate dehydrogenase (DHODH), is necessary for the de novo synthesis of these pyrimidine ribonucleotides, which in turn fulfills the metabolic needs that are necessary for clonal expansion of lymphocytes. ${ }^{108,109}$ By preventing the synthesis of DHODH, teriflunomide actively reduces the pyrimidine ribonucleotide levels, stalls mitosis and further lymphocyte proliferation, and thus protects neurons from autoimmune damage. Teriflunomide also acts by inhibiting protein tyrosine kinases, leading to decreased $\mathrm{T}$ cell proliferation, and by shifting the cytokine profile to prevent inflammation (ie, inhibiting synthesis of proinflammatory cytokines and promoting anti-inflammatory cytokines). ${ }^{110}$ EAE animal models treated with teriflunomide showed a significant reduction in axonal damage by up to $96 \%$, nonlatency or delay of motor-evoked potentials, and preservation of the anatomical integrity in 
both the ascending and descending tracts of the spinal cord, thus underscoring its direct effect on neuroprotection. ${ }^{111,112}$

The TEMSO (Teriflunomide Multiple Sclerosis Oral) trial $^{68}$ illustrated the efficacy of Aubagio ${ }^{\circledR}$ (Genzyme, Boston, MA, USA) as an MS DMT (Table 2), demonstrating nearly $31 \%$ reduction in ARR, a longer time to first relapse, approximately $20 \%$ decrease in disability progression, and a decrease in Gd-MRI lesion activity when compared to placebo. Recent animal studies have shown that teriflunomide can significantly improve motor function and decrease the probability of debilitating paralysis, suggesting that it might become one of the early treatment drugs for MS. ${ }^{111}$ To this end, a Phase III clinical trial (TOPIC [Phase III Study with Teriflunomide Versus Placebo in Patients with First Clinical Symptom of Multiple Sclerosis]; ClinicalTrials.gov NCT00622700) ${ }^{113}$ is ongoing, with an expected study completion date of August 2015, that will inform the utility of teriflunomide in early clinical treatment.

\section{Fingolimod}

Levels of T cells and B cells are regulated through a circulatory mechanism between the blood and appropriate secondary lymphoid organs (SLOs), and the homing of T cells from the blood to sites of inflammation in the CNS is crucial for MS pathogenesis. The MBP-activated T cells breach the $\mathrm{BBB}$, reach the site of inflammation, become encephalitogenic effector cells, and initiate demyelination within the CNS. ${ }^{114}$ An extracellular signaling molecule, sphingosine-1phosphate (S1P), regulates the process of trafficking T cells and B cells from the lymph to the blood. ${ }^{115}$ The S1P receptors, when activated, induce egress of $\mathrm{T}$ cells (naïve) from peripheral blood and sequester them within the SLOs, thus decreasing $\mathrm{T}$ cell levels in the blood. ${ }^{106,116-118}$

FTY720 (2-amino-[2-\{4-octylphenyl $\}$ ethyl]-1, 3-propanediol hydrochloride), a synthetic S1P analogue, immunomodulates the S1P receptors and revises the T cells' migratory pathway (ie, prevents emigration of activated T cells from lymph nodes and sequesters them within SLOs). ${ }^{118}$ This sequestration dramatically reduces the availability of $\mathrm{T}$ cells in the blood that can infiltrate the BBB and home in to the inflamed cells in the CNS. Thus, FTY720 (Fingolimod, Gilenya $^{\circledR}$; Novartis) effectively confers neuroprotection against demyelination. ${ }^{119-121}$ In murine models, FTY720 dramatically reduced the expression of the proinflammatory Th1-type cytokines due to the absence of $\mathrm{T}$ cell migrants to promote further inflammation. ${ }^{122}$ In addition, FTY720 is also suggested to promote remyelination of neurons in the CNS via direct interaction with oligodendrocytes. ${ }^{123}$

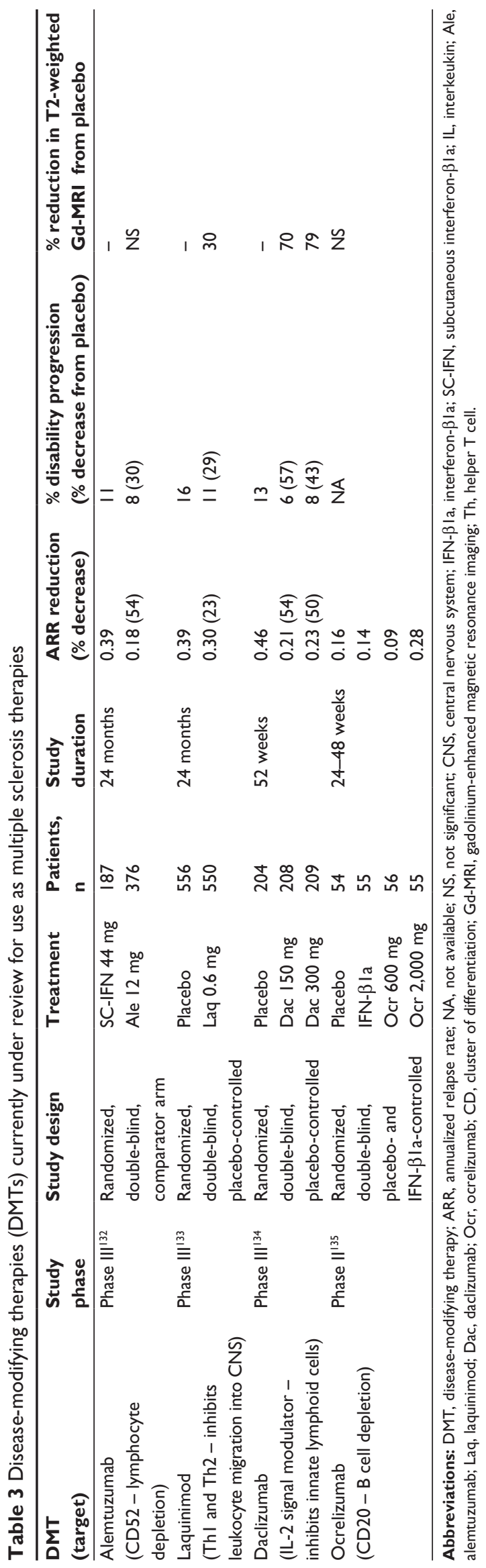


The FREEDOMS (FTY720 Research Evaluating Effects of Daily Oral Therapy in Multiple Sclerosis) study ${ }^{124}$ tested two doses $(0.5 \mathrm{mg}$ or $1.25 \mathrm{mg}$ ) of fingolimod or placebo taken once daily for 24 months. Results showed that patients treated with fingolimod had an approximately $70 \%$ decrease in MS disease activity and a stable EDSS score (Table 2), and about $50 \%$ of patients had no change in T2-weighted MRI lesions. ${ }^{124}$ In a head-to-head comparison with IFN- $\beta 1$ a (TRANSFORMS [Trial Assessing Injectable Interferon Versus FTY720 Oral in Relapsing-Remitting Multiple Sclerosis]), RRMS patients on fingolimod on average had lower ARRs, significantly fewer new or enlarged T2-weighted MRI lesions, and a stable EDSS score (Table 2). ${ }^{125}$ Despite its promising efficacy, fingolimod's safety profile has been challenging, with occurrence of bradyarrhythmias that have caused deaths and elicited prolonged cardiac monitoring for first dosings. ${ }^{126}$ Death of MS patients who were administered fingolimod in the presence of varicella zoster viral infection has also been reported. ${ }^{127} \mathrm{~A}$ first case of PML in the absence of prior natalizumab therapy has also been identified. ${ }^{128}$ Research reports on the safety and efficacy of fingolimod are still emerging, and additional data will further inform the risks versus benefits of this drug for MS therapy.

\section{MS therapy: past, present, and future}

Great strides have been made in the last 20 years in MS therapeutics, beginning with the initial INF- $\beta$-positive trials up through the recent approval of DMF. A number of newer agents are poised potentially to gain approval over the next few years, which we have briefly touched upon (Table 3). Incremental improvements in efficacy have been seen together with improved odds of disease stability with therapy and the potential for disease improvement with some agents.

As discussed earlier, most agents modify the disease course primarily through anti-inflammatory pathways, although the newest entrant (DMF) may well be efficacious in utilizing a novel antioxidant pathway. However, all these agents carry adverse side effects of varying degrees, and hence a thorough evaluation of the risk-benefit ratio for the individual patient is imperative prior to drug administration (Figure 1). In MS, T cells are known to attack three different antigens: MBP, myelin oligodendrocyte glycoprotein, and proteolipid protein. The heterogeneity of MS disease is vast, and each patient's antibody signature varies: the antigen epitopes that elicit antibody response differ among people, and so does the mechanism of "epitope spreading," wherein autoreactive T cell activation is elicited by new epitopes secondary to the dominant epitope, either due to their physical proximity or molecular similarity to the dominant epitope, resulting in sequential self-damage. Currently, ways to personalize MS treatment by recognizing these individual epitopes and formulating corresponding antibodies are being explored. Remyelinating agents are actively under investigation, and may yield novel strategies to increase neuronal functionality and survival in the coming

\section{Optimizing the risk/efficacy balance}
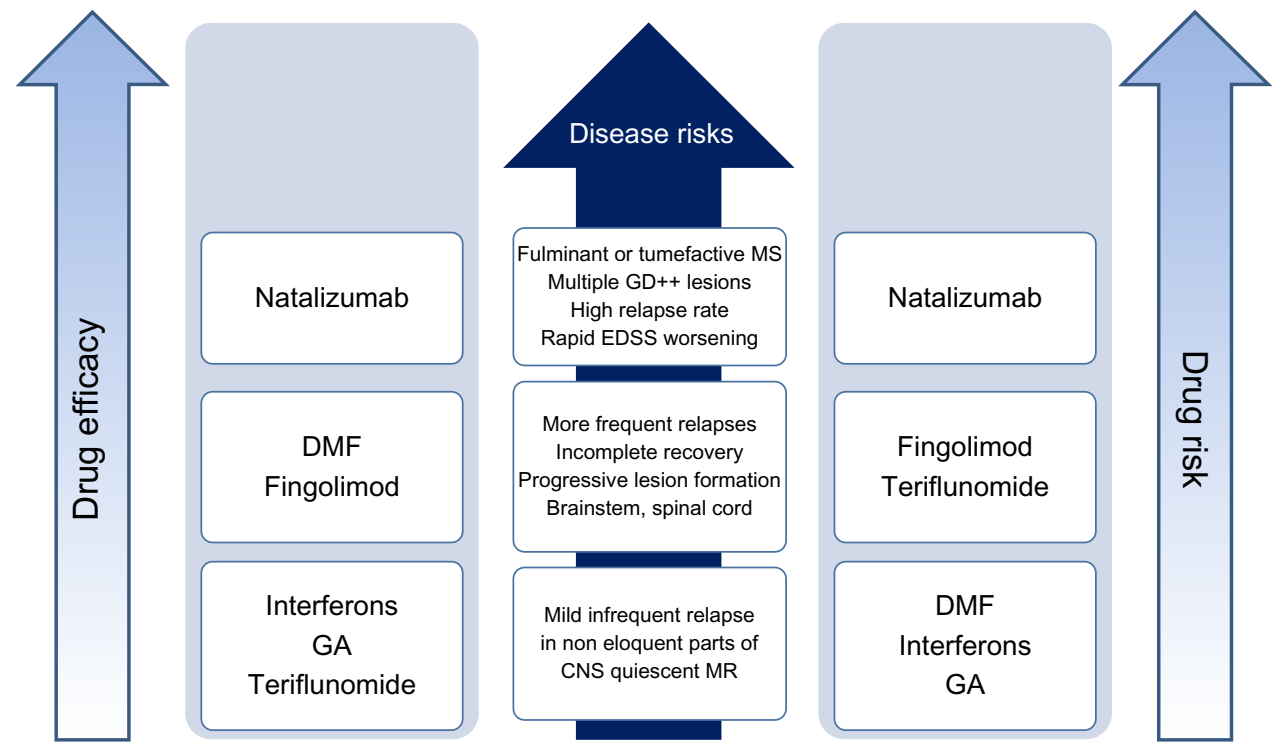

Figure I Optimizing the risk/efficacy balance of approved MS therapeutics: a physician perspective

Abbreviations: DMF, dimethyl fumarate; GA, glatiramer acetate; MS, Multiple Sclerosis; EDSS, Expanded Disability Status Scale; MR, magnetic resonance; CNS, central nervous system. 
years. With preclinical animal trials showing superior efficacy in alleviating MS symptoms, ongoing human clinical trials are investigating the use of hematopoietic and mesenchymal stem cells for effective management of MS. While the goal of hematopoietic stem cell transplantation is refurbishing the aberrant $\mathrm{T}$ cell population with nonautoreactive $\mathrm{T}$ cells, mesenchymal stem cell transplantation can potentially promote neural restoration. MS therapeutics is now an area of rapid evolution, with broadening biological targets and ongoing improvement in efficacy.

\section{Disclosure}

Dr Foley has received personal compensation for consulting, speaking and scientific advisory boards from Genzyme, Biogen Idec Inc. and Teva. Dr Foley has also received research support from Biogen Idec Inc., Genzyme, Teva and Avanir. The other authors report no conflicts of interest in this work.

\section{References}

1. Polman CH, O'Connor PW, Havrdova E, et al. A randomized, placebocontrolled trial of natalizumab for relapsing multiple sclerosis. $\mathrm{N} \mathrm{Engl}$ J Med. 2006;354(9):899-910.

2. Williams R, Rigby AS, Airey M, Robinson M, Ford H. Multiple sclerosis: its epidemiological, genetic, and health care impact. J Epidemiol Community Health. 1995;49(6):563-569.

3. Compston A, Coles A. Multiple sclerosis. Lancet. 2002;359(9313): 1221-1231.

4. Compston A, Coles A. Multiple sclerosis. Lancet. 2008;372(9648): 1502-1517.

5. Keegan BM, Noseworthy JH. Multiple sclerosis. Ann Rev Medic. 2002;53:285-302.

6. Koch-Henriksen N. The Danish Multiple Sclerosis Registry: a 50-year follow-up. Mult Scler. 1999;5(4):293-296.

7. Mayr WT, Pittock SJ, McClelland RL, Jorgensen NW, Noseworthy JH, Rodriguez M. Incidence and prevalence of multiple sclerosis in Olmsted County, Minnesota, 1985-2000. Neurology. 2003;61(10):1373-1377.

8. Hawkins SA, McDonnell GV. Benign multiple sclerosis? Clinical course, long term follow up, and assessment of prognostic factors. J Neurol Neurosurg Psychiatry. 1999;67(2):148-152.

9. Whitacre CC, Reingold SC, O'Looney PA, et al. A gender gap in autoimmunity: Task Force on Gender, Multiple Sclerosis and Autoimmunity. Science. 1999;283(5406):1277-1278.

10. Orton SM, Herrera BM, Yee IM, et al. Sex ratio of multiple sclerosis in Canada: a longitudinal study. Lancet Neurol. 2006;5(11):932-936.

11. Kister I, Chamot E, Salter AR, Cutter GR, Bacon TE, Herbert J. Disability in multiple sclerosis: a reference for patients and clinicians. Neurology. 2013;80(11):1018-1024.

12. Sadovnick AD, Ebers GC, Wilson RW, Paty DW. Life expectancy in patients attending multiple sclerosis clinics. Neurology. 1992;42(5): 991-994.

13. Charcot JM. Histologie de la sclerose en plaques. Gaz Hop Civ Mil Empire Ottoman. 1868;41:554-555.

14. Polman $\mathrm{CH}$, Reingold SC, Banwell B, et al. Diagnostic criteria for multiple sclerosis: 2010 revisions to the McDonald criteria. Ann Neurol. 2011;69(2):292-302.

15. Stangel M, Fredrikson S, Meinl E, Petzold A, Stuve O, Tumani H. The utility of cerebrospinal fluid analysis in patients with multiple sclerosis. Nat Rev Neurol. 2013;9(5):267-276.
16. Kuenz B, Deisenhammer F, Berger T, Reindl M. Diagnostic biomarkers in multiple sclerosis. Expert Opinion Medical Diagn. 2007;1(2): 225-233.

17. Katsavos S, Anagnostouli M. Biomarkers in multiple sclerosis: an up-to-date overview. Mult Scler Int. 2013;2013:340508.

18. Leone MA, Barizzone N, Esposito F, et al. Association of genetic markers with CSF oligoclonal bands in multiple sclerosis patients. PloS One. 2013;8(6):e64408.

19. Rudick RA. The elusive biomarker for personalized medicine in multiple sclerosis: the search continues. Neurology. 2012;79(6):498-499.

20. Oberwahrenbrock T, Schippling S, Ringelstein M, et al. Retinal damage in multiple sclerosis disease subtypes measured by high-resolution optical coherence tomography. Mult Scler Int. 2012;2012:530305.

21. Vukusic S, Confavreux C. Primary and secondary progressive multiple sclerosis. J Neurol Sci. 2003;206(2):153-155.

22. Hagman S, Raunio M, Rossi M, Dastidar P, Elovaara I. Diseaseassociated inflammatory biomarker profiles in blood in different subtypes of multiple sclerosis: prospective clinical and MRI follow-up study. J Neuroimmunol. 2011;234(1-2):141-147.

23. Freedman MS, Selchen D, Arnold DL, et al. Treatment optimization in MS: Canadian MS Working Group updated recommendations. Can J Neurol Sci. 2013;40(3):307-323.

24. Kieseier BC, Wiendl H, Hemmer B, Hartung HP. Treatment and treatment trials in multiple sclerosis. Curr Opin Neurol. 2007;20(3): 286-293.

25. Spain RI, Cameron MH, Bourdette D. Recent developments in multiple sclerosis therapeutics. BMC Med. 2009;7:74.

26. Filippini G, Brusaferri F, Sibley WA, et al. Corticosteroids or ACTH for acute exacerbations in multiple sclerosis. Cochrane Database Syst Rev. 2000;(4):CD001331.

27. Rudick RA, Cohen JA, Weinstock-Guttman B, Kinkel RP, Ransohoff RM. Management of multiple sclerosis. $N$ Engl J Med. 1997;337(22):1604-1611.

28. Berkovich R. Treatment of acute relapses in multiple sclerosis. Neurotherapeutics. 2013;10(1):97-105.

29. Burton JM, O'Connor PW, Hohol M, Beyene J. Oral versus intravenous steroids for treatment of relapses in multiple sclerosis. Cochrane Database Syst Rev. 2012;12:CD006921.

30. Myhr KM, Mellgren SI. Corticosteroids in the treatment of multiple sclerosis. Acta Neurologica Scand Suppl. 2009;(189):73-80.

31. Lassmann H. Pathology and disease mechanisms in different stages of multiple sclerosis. J Neurol Sci. Epub June 2, 2013.

32. Bø L, Esiri M, Evangelou N, Kuhlmann T. Demyelination and remyelination in multiple sclerosis. In: Duncan ID, Franklin RJM, editors. Myelin Repair and Neuroprotection in Multiple Sclerosis. New York: Springer; 2013:23-45.

33. Crayton H, Heyman RA, Rossman HS. A multimodal approach to managing the symptoms of multiple sclerosis. Neurology. 2004; 63(11 Suppl 5):S12-S18.

34. Kurtzke JF. Rating neurologic impairment in multiple sclerosis: an expanded disability status scale (EDSS). Neurology. 1983;33(11): 1444-1452.

35. Weinstock-Guttman B, Ransohoff RM, Kinkel RP, Rudick RA. The interferons: biological effects, mechanisms of action, and use in multiple sclerosis. Ann Neurol. 1995;37(1):7-15.

36. Lin L. Betaseron. Dev Biol Stand. 1998;96:97-104.

37. Weber F, Janovskaja J, Polak T, Poser S, Rieckmann P. Effect of interferon beta on human myelin basic protein-specific T-cell lines: comparison of IFNbeta-1a and IFNbeta-1b. Neurology. 1999;52(5): 1069-1071.

38. Rudick RA, Ransohoff RM, Lee JC, et al. In vivo effects of interferon beta-1a on immunosuppressive cytokines in multiple sclerosis. Neurology. 1998;50(5):1294-1300.

39. Yong VW, Chabot S, Stuve O, Williams G. Interferon beta in the treatment of multiple sclerosis: mechanisms of action. Neurology. 1998; 51(3):682-689.

40. Kieseier BC. The mechanism of action of interferon-beta in relapsing multiple sclerosis. CNS Drugs. 2011;25(6):491-502. 
41. Paty DW, Li DK. Interferon beta-1b is effective in relapsing-remitting multiple sclerosis. II. MRI analysis results of a multicenter, randomized, double-blind, placebo-controlled trial. UBC MS/MRI Study Group and the IFNB Multiple Sclerosis Study Group. Neurology. 1993;43(4):662-667.

42. [No authors listed]. Interferon beta- $1 \mathrm{~b}$ is effective in relapsing-remitting multiple sclerosis. I. Clinical results of a multicenter, randomized, double-blind, placebo-controlled trial. The IFNB Multiple Sclerosis Study Group. Neurology. 1993;43(4):655-661.

43. Jacobs LD, Cookfair DL, Rudick RA, et al. Intramuscular interferon beta-1a for disease progression in relapsing multiple sclerosis. Ann Neurol. 1996;39(3):285-294.

44. Fernandez O, Antiquedad A, Arbizu T, et al. Treatment of relapsingremitting multiple sclerosis with natural interferon beta: a multicenter, randomized clinical trial. Mult Scler. 1995; 1 Suppl 1:S67-S69.

45. Ponomarenko NA, Durova OM, Vorobiev II, et al. Autoantibodies to myelin basic protein catalyze site-specific degradation of their antigen. Proc Natl Acad Sci U S A. 2006;103(2):281-286.

46. Ponomarenko NA, Durova OM, Vorobiev II, et al. Catalytic activity of autoantibodies toward myelin basic protein correlates with the scores on the multiple sclerosis expanded disability status scale. Immunol Lett. 2006;103(1):45-50.

47. Valli A, Sette A, Kappos L, et al. Binding of myelin basic protein peptides to human histocompatibility leukocyte antigen class II molecules and their recognition by $\mathrm{T}$ cells from multiple sclerosis patients. J Clin Invest. 1993;91(2):616-628.

48. Ota K, Matsui M, Milford EL, Mackin GA, Weiner HL, Hafler DA. T-cell recognition of an immunodominant myelin basic protein epitope in multiple sclerosis. Nature. 1990;346(6280):183-187.

49. Wolinsky JS. Copolymer 1: a most reasonable alternative therapy for early relapsing-remitting multiple sclerosis with mild disability. Neurology. 1995;45(7):1245-1247.

50. Fridkis-Hareli M, Teitelbaum D, Gurevich E, et al. Direct binding of myelin basic protein and synthetic copolymer 1 to class II major histocompatibility complex molecules on living antigen-presenting cells specificity and promiscuity. Proc Natl Acad Sci U S A. 1994;91(11): 4872-4876.

51. Gran B, Tranquill LR, Chen M, et al. Mechanisms of immunomodulation by glatiramer acetate. Neurology. 2000;55(11):1704-1714.

52. Berger A. Th1 and Th2 responses: what are they? BMJ. 2000; 321(7258):424.

53. Johnson KP, Brooks BR, Cohen JA, et al. Copolymer 1 reduces relapse rate and improves disability in relapsing-remitting multiple sclerosis: results of a phase III multicenter, double-blind placebo-controlled trial. The Copolymer 1 Multiple Sclerosis Study Group. Neurology. 1995;45(7):1268-1276.

54. Korczyn AD, Nisipeanu P. Safety profile of copolymer 1: analysis of cumulative experience in the United States and Israel. $J$ Neurol. 1996;243(4 Suppl 1):S23-S26.

55. Munari L, Lovati R, Boiko A. Therapy with glatiramer acetate for multiple sclerosis. Cochrane Database Syst Rev. 2004;(1):CD004678.

56. La Mantia L, Munari LM, Lovati R. Glatiramer acetate for multiple sclerosis. Cochrane Database Syst Rev. 2010;(5):CD004678.

57. Yednock TA, Cannon C, Fritz LC, Sanchez-Madrid F, Steinman L, Karin N. Prevention of experimental autoimmune encephalomyelitis by antibodies against alpha 4 beta 1 integrin. Nature. 1992; 356(6364):63-66.

58. Leger OJ, Yednock TA, Tanner L, et al. Humanization of a mouse antibody against human alpha-4 integrin: a potential therapeutic for the treatment of multiple sclerosis. Hum Antibodies. 1997;8(1):3-16.

59. Kent SJ, Karlik SJ, Rice GP, Horner HC. A monoclonal antibody to alpha 4-integrin reverses the MR-detectable signs of experimental allergic encephalomyelitis in the guinea pig. J Magn Reson Imaging. 1995;5(5):535-540.

60. Miller DH, Khan OA, Sheremata WA, et al. A controlled trial of natalizumab for relapsing multiple sclerosis. $N$ Engl J Med. 2003; 348(1):15-23.
61. Kent SJ, Karlik SJ, Cannon C, et al. A monoclonal antibody to alpha 4 integrin suppresses and reverses active experimental allergic encephalomyelitis. J Neuroimmunol. 1995;58(1):1-10.

62. Elices MJ. Natalizumab. Elan/Biogen. Curr Opin Investig Drugs. 2003;4(11):1354-1362.

63. Bauer M, Brakebusch C, Coisne C, et al. Beta1 integrins differentially control extravasation of inflammatory cell subsets into the CNS during autoimmunity. Proc Natl Acad Sci U S A. 2009;106(6): 1920-1925.

64. Coisne C, Mao W, Engelhardt B. Cutting edge: natalizumab blocks adhesion but not initial contact of human $\mathrm{T}$ cells to the blood-brain barrier in vivo in an animal model of multiple sclerosis. J Immunol. 2009;182(10):5909-5913.

65. Sheremata WA, Vollmer TL, Stone LA, Willmer-Hulme AJ, Koller M. A safety and pharmacokinetic study of intravenous natalizumab in patients with MS. Neurology. 1999;52(5):1072-1074.

66. O'Connor P, Miller D, Riester K, et al. Relapse rates and enhancing lesions in a phase II trial of natalizumab in multiple sclerosis. Mult Scler. 2005;11(5):568-572.

67. Sheremata WA, Minagar A, Alexander JS, Vollmer T. The role of alpha-4 integrin in the aetiology of multiple sclerosis: current knowledge and therapeutic implications. CNS Drugs. 2005;19(11):909-922.

68. O'Connor P. Natalizumab and the role of alpha 4-integrin antagonism in the treatment of multiple sclerosis. Expert Opin Biol Ther. 2007;7(1):123-136.

69. Miller DH, Soon D, Fernando KT, et al. MRI outcomes in a placebocontrolled trial of natalizumab in relapsing MS. Neurology. 2007; 68(17):1390-1401

70. Rudick RA, Miller D, Hass S, et al. Health-related quality of life in multiple sclerosis: effects of natalizumab. Ann Neurol. 2007; 62(4):335-346.

71. Balcer LJ, Galetta SL, Calabresi PA, et al. Natalizumab reduces visual loss in patients with relapsing multiple sclerosis. Neurology. 2007; 68(16):1299-1304.

72. Phillips JT, Giovannoni G, Lublin FD, et al. Sustained improvement in Expanded Disability Status Scale as a new efficacy measure of neurological change in multiple sclerosis: treatment effects with natalizumab in patients with relapsing multiple sclerosis. Mult Scler. 2011;17(8):970-979.

73. Weinstock-Guttman B, Galetta SL, Giovannoni G, et al. Additional efficacy endpoints from pivotal natalizumab trials in relapsing-remitting MS. J Neurol. 2012;259(5):898-905.

74. Cadavid D, Jurgensen S, Lee S. Impact of natalizumab on ambulatory improvement in secondary progressive and disabled relapsing-remitting multiple sclerosis. PloS One. 2013;8(1):e53297.

75. Rudick RA, Stuart WH, Calabresi PA, et al. Natalizumab plus interferon beta-1a for relapsing multiple sclerosis. N Engl J Med. March 2, 2006;354(9):911-923.

76. Biogen Idec. Tysabri (natalizumab): benefit/risk update and PML risk stratification. 2013. Available from: http://www.slideshare.net/ gavingiovannoni/natalizuman. Accessed September 17, 2013

77. Bloomgren G, Richman S, Hotermans C, et al. Risk of natalizumabassociated progressive multifocal leukoencephalopathy. $N$ Engl J Med. 2012;366(20):1870-1880.

78. Plavina T, Subramanyam M, Bloomgren G, et al. Use of JC virus antibody index to stratify risk of progressive multifocal leukoencephalopathy in natalizumab-treated patients with multiple sclerosis. Poster presented at: 27th Annual Meeting of the CMSC and the Fifth Cooperative Meeting of the CMSC-ACTRIMS; May 29-June 1, 2013; Orlando, FL.

79. Schwab N, Schneider-Hohendorf T, Posevitz V, et al. L-selectin is a possible biomarker for individual PML risk in natalizumab-treated MS patients. Neurology. 2013;81(10):865-871.

80. Foley JF. Natalizumab related PML: an evolving risk stratification paradigm. Poster presented at: American Academy of Neurology 2013 Annual Meeting; March 16-23, 2013; San Diego, CA.

81. Gonsette RE. Neurodegeneration in multiple sclerosis: the role of oxidative stress and excitotoxicity. J Neurol Sci. 2008;274(1-2):48-53. 
82. Brosnan CF, Cannella B, Battistini L, Raine CS. Cytokine localization in multiple sclerosis lesions: correlation with adhesion molecule expression and reactive nitrogen species. Neurology. 1995;45(6 Suppl 6):S16-S21.

83. Wierinckx A, Brevé J, Mercier D, Schultzberg M, Drukarch B, Van Dam AM. Detoxication enzyme inducers modify cytokine production in rat mixed glial cells. J Neuroimmunol. 2005;166(1-2): 132-143.

84. Miller E, Wachowicz B, Majsterek I. Advances in antioxidative therapy of multiple sclerosis. Current medicinal chemistry. Epub June 25, 2013.

85. Bogdan C. Nitric oxide and the immune response. Nat Immunol. 2001;2(10):907-916.

86. Nathan C, Shiloh MU. Reactive oxygen and nitrogen intermediates in the relationship between mammalian hosts and microbial pathogens Proc Natl Acad Sci U S A. 2000;97(16):8841-8848.

87. Hibbs JB Jr, Taintor RR, Vavrin Z, Rachlin EM. Nitric oxide: a cytotoxic activated macrophage effector molecule. Biochem Biophys Res Commun. 1988;157(1):87-94.

88. Smith KJ, Kapoor R, Felts PA. Demyelination: the role of reactive oxygen and nitrogen species. Brain Pathol. 1999;9(1):69-92.

89. Su KG, Banker G, Bourdette D, Forte M. Axonal degeneration in multiple sclerosis: the mitochondrial hypothesis. Curr Neurol Neurosci Rep. 2009;9(5):411-417.

90. Albrecht P, Bouchachia I, Goebels N, et al. Effects of dimethyl fumarate on neuroprotection and immunomodulation. J Neuroinflammation. 2012;9:163.

91. Schilling S, Goelz S, Linker R, Luehder F, Gold R. Fumaric acid esters are effective in chronic experimental autoimmune encephalomyelitis and suppress macrophage infiltration. Clin Exp Immunol. 2006;145(1):101-107.

92. Vandermeeren M, Janssens S, Borgers M, Geysen J. Dimethylfumarate is an inhibitor of cytokine-induced E-selectin, VCAM-1, and ICAM-1 expression in human endothelial cells. Biochem Biophys Res Commun. 1997;234(1):19-23

93. Linker RA, Lee DH, Ryan S, et al. Fumaric acid esters exert neuroprotective effects in neuroinflammation via activation of the Nrf2 antioxidant pathway. Brain. 2011;134(3):678-692.

94. Kohen R, Nyska A. Oxidation of biological systems: oxidative stress phenomena, antioxidants, redox reactions, and methods for their quantification. Toxicol Pathol. 2002;30(6):620-650.

95. Scannevin RH, Chollate S, Jung MY, et al. Fumarates promote cytoprotection of central nervous system cells against oxidative stress via the nuclear factor (erythroid-derived 2)-like 2 pathway. J Pharmacol Exp Ther. 2012;341(1):274-284.

96. Schimrigk S, Brune N, Hellwig K, et al. Oral fumaric acid esters for the treatment of active multiple sclerosis: an open-label, baselinecontrolled pilot study. Eur J Neurol. 2006;13(6):604-610.

97. Wakkee M, Thio HB. Drug evaluation: BG-12, an immunomodulatory dimethylfumarate. Curr Opinion Investig Drugs. 2007 8(11):955-962.

98. Kappos L, Gold R, Miller DH, et al. Efficacy and safety of oral fumarate in patients with relapsing-remitting multiple sclerosis: a multicentre, randomised, double-blind, placebo-controlled phase IIb study. Lancet. 2008;372(9648):1463-1472.

99. Gold R, Kappos L, Arnold DL, et al. Placebo-controlled phase 3 study of oral BG-12 for relapsing multiple sclerosis. N Engl J Med. 2012; 367(12):1098-1107.

100. Fox RJ, Miller DH, Phillips JT, et al. Placebo-controlled phase 3 study of oral BG-12 or glatiramer in multiple sclerosis. $N$ Engl J Med 2012;367(12):1087-1097.

101. Hutchinson M, Fox RJ, Miller DH, et al. Clinical efficacy of BG-12 (dimethyl fumarate) in patients with relapsing-remitting multiple sclerosis: subgroup analyses of the CONFIRM study. Journal of Neurology. 2013;260(9):2286-2296.

102. Ermis U, Weis J, Schulz JB. PML in a patient treated with fumaric acid. $N$ Engl J Med. 2013;368(17):1657-1658.
103. van Oosten BW, Killestein J, Barkhof F, Polman CH, Wattjes MP. PML in a patient treated with dimethyl fumarate from a compounding pharmacy. N Engl J Med. 2013;368(17):1658-1659.

104. Sweetser MT, Dawson KT, Bozic C. Manufacturer's response to case reports of PML. N Engl J Med. 2013;368(17):1659-1661.

105. Zeyda M, Poglitsch M, Geyeregger R, et al. Disruption of the interaction of $\mathrm{T}$ cells with antigen-presenting cells by the active leflunomide metabolite teriflunomide: involvement of impaired integrin activation and immunologic synapse formation. Arthritis Rheum. 2005;52(9):2730-2739.

106. O'Connor PW, Li D, Freedman MS, et al. A Phase II study of the safety and efficacy of teriflunomide in multiple sclerosis with relapses. Neurology. 2006;66(6):894-900

107. Warnke C, Meyer zu Hörste G, Hartung HP, Stüve O, Kieseier BC. Review of teriflunomide and its potential in the treatment of multiple sclerosis. Neuropsychiatr Dis Treat. 2009;5:333-340.

108. Fox RI, Herrmann ML, Frangou CG, et al. Mechanism of action for leflunomide in rheumatoid arthritis. Clin Immunol. 1999;93(3): 198-208.

109. Herrmann ML, Schleyerbach R, Kirschbaum BJ. Leflunomide: an immunomodulatory drug for the treatment of rheumatoid arthritis and other autoimmune diseases. Immunopharmacology. 2000;47(2-3): 273-289.

110. Oh J, O'Connor PW. Teriflunomide for the treatment of multiple sclerosis. Semin Neurol. 2013;33(1):45-55.

111. Iglesias-Bregna D, Hanak S, Ji Z, et al. Effects of prophylactic and therapeutic teriflunomide in transcranial magnetic stimulation-induced motor-evoked potentials in the Dark Agouti rat model of experimental autoimmune encephalomyelitis. J Pharmacol Exp Ther. Epub Jul 26.

112. Merrill JE, Hanak S, Pu SF, et al. Teriflunomide reduces behavioral, electrophysiological, and histopathological deficits in the Dark Agouti rat model of experimental autoimmune encephalomyelitis. J Neurol. 2009;256(1):89-103.

113. Sanofi. Phase III Study With Teriflunomide Versus Placebo in Patients With First Clinical Symptom of Multiple Sclerosis (TOPIC). Available from: http://clinicaltrials.gov/show/NCT00622700. Identifier: NCT00622700. Accessed September 27, 2013.

114. Olsson T, Zhi WW, Höjeberg B, et al. Autoreactive T lymphocytes in multiple sclerosis determined by antigen-induced secretion of interferon-gamma. J Clin Invest. 1990;86(3):981-985.

115. Mandala S, Hajdu R, Bergstrom J, et al. Alteration of lymphocyte trafficking by sphingosine-1-phosphate receptor agonists. Science. 2002;296(5566):346-349.

116. Yopp AC, Randolph GJ, Bromberg JS. Leukotrienes, sphingolipids, and leukocyte trafficking. J Immunol. 2003;171(1):5-10.

117. O'Sullivan C, Dev KK. The structure and function of the S1P1 receptor. Trends Pharmacol Sci. 2013;34(7):401-412.

118. Xie JH, Nomura N, Koprak SL, Quackenbush EJ, Forrest MJ, Rosen H. Sphingosine-1-phosphate receptor agonism impairs the efficiency of the local immune response by altering trafficking of naive and antigenactivated CD4+ T cells. J Immunol. 2003;170(7):3662-3670.

119. Yanagawa Y, Masubuchi Y, Chiba K. FTY720, a novel immunosuppressant, induces sequestration of circulating mature lymphocytes by acceleration of lymphocyte homing in rats, III. Increase in frequency of CD62L-positive T cells in Peyer's patches by FTY720-induced lymphocyte homing. Immunology. 1998;95(4):591-594.

120. Yanagawa Y, Sugahara K, Kataoka H, Kawaguchi T, Masubuchi Y, Chiba K. FTY720, a novel immunosuppressant, induces sequestration of circulating mature lymphocytes by acceleration of lymphocyte homing in rats. II. FTY720 prolongs skin allograft survival by decreasing $\mathrm{T}$ cell infiltration into grafts but not cytokine production in vivo. J Immunol. 1998;160(11):5493-5499.

121. Chiba K, Yanagawa Y, Masubuchi Y, et al. FTY720, a novel immunosuppressant, induces sequestration of circulating mature lymphocytes by acceleration of lymphocyte homing in rats. I. FTY720 selectively decreases the number of circulating mature lymphocytes by acceleration of lymphocyte homing. J Immunol. 1998;160(10): 5037-5044. 
122. Fujino M, Funeshima N, Kitazawa Y, et al. Amelioration of experimental autoimmune encephalomyelitis in Lewis rats by FTY720 treatment. J Pharmacol Exp Ther. 2003;305(1):70-77.

123. Miron VE, Ludwin SK, Darlington PJ, et al. Fingolimod (FTY720) enhances remyelination following demyelination of organotypic cerebellar slices. Am J Pathol. 2010;176(6):2682-2694.

124. Kappos L, Radue EW, O’Connor P, et al. A placebo-controlled trial of oral fingolimod in relapsing multiple sclerosis. $N$ Engl $\mathrm{J} \mathrm{Med}$. 2010;362(5):387-401.

125. Cohen JA, Barkhof F, Comi G, et al. Oral fingolimod or intramuscular interferon for relapsing multiple sclerosis. $N$ Engl J Med. 2010;362(5):402-415.

126. Lindsey JW, Haden-Pinneri K, Memon NB, Buja LM. Sudden unexpected death on fingolimod. Mult Scler. 2012;18(10):1507-1508.

127. Ratchford JN, Costello K, Reich DS, Calabresi PA. Varicella-zoster virus encephalitis and vasculopathy in a patient treated with fingolimod. Neurology. 2012;79(19):2002-2004.

128. Rukovets O. FDA investigates PML in patient taking Gilenya. 2013. Available from: http://journals.lww.com/neurotodayonline/blog/ breakingnews/pages/post.aspx?PostID=240. Accessed September 17, 2013.

129. Jacobs LD, Cookfair DL, Rudick RA, et al. Intramuscular interferon beta-1a for disease progression in relapsing multiple sclerosis. The Multiple Sclerosis Collaborative Research Group (MSCRG). Ann Neurol. 1996;39(3):285-294.
130. [No authors listed]. Randomised double-blind placebo-controlled study of interferon beta-1a in relapsing/remitting multiple sclerosis. PRISMS (Prevention of Relapses and Disability by Interferon beta1a Subcutaneously in Multiple Sclerosis) Study Group. Lancet. 1998;352(9139):1498-1504.

131. O'Connor P, Wolinsky JS, Confavreux C, et al. Randomized trial of oral teriflunomide for relapsing multiple sclerosis. $N$ Engl J Med. 2011;365(14):1293-1303.

132. Cohen JA, Coles AJ, Arnold DL, et al. Alemtuzumab versus interferon beta 1a as first-line treatment for patients with relapsing-remitting multiple sclerosis: a randomised controlled phase 3 trial. Lancet. 2012;380(9856):1819-1828.

133. Comi G, Jeffery D, Kappos L, et al. Placebo-controlled trial of oral laquinimod for multiple sclerosis. N Engl J Med. 2012;366(11): 1000-1009.

134. Gold R, Giovannoni G, Selmaj K, et al. Daclizumab high-yield process in relapsing-remitting multiple sclerosis (SELECT): a randomised, double-blind, placebo-controlled trial. Lancet. 2013; 381(9884):2167-2175.

135. Kappos L, Li D, Calabresi PA, et al. Ocrelizumab in relapsingremitting multiple sclerosis: a phase 2, randomised, placebo-controlled, multicentre trial. Lancet. 2011;378(9805):1779-1787.
Biologics: Targets \& Therapy

\section{Publish your work in this journal}

Biologics: Targets \& Therapy is an international, peer-reviewed journal focusing on the patho-physiological rationale for and clinical application of Biologic agents in the management of autoimmune diseases, cancers or other pathologies where a molecular target can be identified. This journal is indexed on PubMed Central, CAS, EMBase, Scopus

\section{Dovepress}

and the Elsevier Bibliographic databases. The manuscript management system is completely online and includes a very quick and fair peerreview system, which is all easy to use. Visit http://www.dovepress. com/testimonials.php to read real quotes from published authors. 